Jarkko Saarinen \& Alix Varnajot (2019) The Arctic in tourism: complementing and contesting perspectives on tourism in the Arctic, Polar Geography, 42:2, 109-124, DOI: 10.1080/1088937X.2019.1578287

This is an Accepted Manuscript of an article published by Taylor \& Francis in Polar geography on 12 Feb 2019, available online: http:// www.tandfonline.com/10.1080/1088937X.2019.1578287.

\title{
The Arctic in tourism: Complementing and contesting perspectives on tourism in the Arctic
}

The economic and political importance of the Arctic has grown considerably in recent decades, and the region's role and visibility in tourism has also significantly increased. The idea of Arctic tourism has been discussed in academia for a long time, but there is no consensus on the definition of the concept. This review paper aims to discuss different perspectives on tourism in the Arctic by utilising literature and selected examples. The outlined perspectives are spatial, produced and experienced Arctic tourism. They are interrelated and, thus, partly complementary, but they can also challenge each other. The perspectives demonstrate different ways to approach and understand various characteristics of Arctic tourism and diversity in tourism in the Arctic. All perspectives of the Arctic in tourism involve both benefits and limitations when thinking about what Arctic tourism is and what it involves. The paper concludes that there is a need to acknowledge the diversity of the Arctic as a changing idea and a geographical region in and for tourism. By acknowledging this, the Arctic would not be characterised mainly by static or external views in tourism but also by internal needs, knowledge, dynamics and concerns for sustainable tourism development in the region.

Keywords: Arctic; Arctic tourism; tourist destination; tourist experience; sustainability

\section{Introduction}

The importance and public visibility of the Arctic has grown considerably in recent decades. The region has become an international policy and academic focal point, due to ongoing and estimated global climate change impacts, its energy resources, and potential future transportation routes opening up due to shrinking ice coverage and longer operational seasons (Hall \& Saarinen, 2010a). In addition, the role and visibility of the Arctic in tourism has significantly increased in recent years (Maher, 2017). Although there is a relatively long history of tourism in the region (see Hall \& Johnston, 1995), the Arctic has quite recently attracted greater public attention (Bystrowska \& Dawson, 2017), leading to specific sites visited by hundreds or even thousands of tourists at the same time.

The idea of the Arctic is transforming as a region with economic and political significance (see Arbo, Iversen, Knol, Ringholm \& Sander, 2013; Dittmer, Moisio, Ingram, \& Dodds, 2011) and as a destination for tourists and tourism development (see Maher, 2007; Viken, 2011). In spite of this 
ongoing and expected future change, the Arctic still seems to relate to images, elements and activities that for most people are related to open empty spaces, extreme environments and adventurous expeditions in rough, frozen, untouched and uncivilised landscapes (Hall \& Johnston, 1995; Hall \& Saarinen, 2010b). Those kinds of representations conveyed by popular narratives, the media, films and myths are typically representative of what the Arctic in tourism is all about (see Fjellestad, 2016; Sæpórsdóttir, Hall \& Saarinen, 2011; Wilson Rowe, 2013). However, these hegemonic images of the Arctic have often been created and steered from outside the region, by outsiders, for outsiders (see Pincus \& Ali, 2016; Viken, 2013). As a result, the Arctic is usually understood and depicted as a singular and peripheral space (Dittmer et al., 2011). However, there is great diversity in the Arctic and there are local and regional actors and processes (Keskitalo, 2007) increasingly emphasising a multitude of meanings and elements that are and can be linked to the place called the Arctic. As noted by Viken (2013, p. 41) "the Arctic is not one destination", as the region is characterised by a wide range of landscapes, ecosystems, climates, people, politics, economies and cultures that also allow for various types of tourism activities (Johnston, 2011; Lee, Weaver \& Prebensen, 2017, Viken \& Müller, 2017).

But how does this diversity of meanings influence the idea of Arctic tourism? It is easy to agree with Maher (2007, p. 2), who stated that "a single definition [for Arctic tourism] is virtually impossible.” Despite the multitude of voices, however, it is crucial to have a conceptual understanding of the dimensions and meanings of Arctic tourism as a phenomenon and/or context and topic. Obviously, this is crucial for academic research but also for policy-making and tourism development strategies, as if our understanding of a concept and phenomenon are poor or limited then the policies that we develop in relation to tourism in the Arctic and the actions that we take are likely to be poor too (see Hall, 2005, p. 15). This is critical, in general, but especially in relation to a need for sustainability in Arctic tourism development (see Saarinen, 2014; Sæpórsdóttir \& Saarinen, 2016).

In this review paper, we argue that the concept of Arctic tourism can be approached based on different perspectives as a diverse, multiscalar and shifting idea. Thus, instead of trying to formulate one distinctive and sound definition, the aim of this paper is to discuss and outline different potential perspectives on the Arctic in tourism based on literature and illustrative selected examples. With these outlined perspectives, our aim is not to answer in detail and definitely questions such as 'what is the Arctic in tourism' or 'what is Arctic tourism'. Instead, we understand Arctic tourism as a contextual idea: we are interested in how the Arctic can be approached and understood in tourism 
and as a tourist destination. In tourism studies, the concept of destination is a problematic one as it can refer to a varying range of spatial scales: continents, states, provinces, municipalities and other administrative units, tourist resorts or even individual tourist products (Saarinen, 2004). Therefore, instead of locking in to a certain scale, the paper focuses on how (based on what) the Arctic can be framed, created and re-created in tourism as a dynamic space.

Our analytical basis is grounded on Leiper's (1979) classical framework of tourism, in which he divided the tourism phenomenon into three elements, namely the geographical, the industrial and the human. As it is a general framework, we have partially modified and re-interpreted it by utilizing Wang's (1999) approach to authenticity in tourist experiences, which he separates into three different types: objective, constructive and existential authenticity. Although tourist experiences are at the core of the existence of tourism as a phenomenon, they represent only one perspective - the human - in Leiper's framework. Here, in the context this paper, we approach tourism from the perspectives of the spatial, produced and experienced Arctics in tourism. The spatial approach of the Arctic as a tourism destination region refers to Leiper's geographical element and relates to experiences that Wang base on the idea of objective authenticity. Leiper's geographical element involves three components that are the generating regions, the transit routes and the destination regions. For the purpose of this article, however, we will focus on the Arctic as the destination region with an understanding that it is part of a wider tourism system. The produced Arctic in tourism relates to Leiper's industrial element and also to Wang's constrictive authenticity relying partly on projected objects by tourism producers. The experienced Arctic is based on the tourists' viewpoints i.e. what Leiper terms as the human element. Obviously, the experienced Arctic relates to all types of authenticity in Wang's approach, but here the connection is emphasised with a highly subjective and individualistic existential authenticity.

By utilising these broad perspectives derived from Leiper's (1979) framework, the aim is to capture different ways in which tourism in the Arctic has been approached and framed in research (see Viken, 2013). These perspectives are interrelated and complementary, but they also offer contesting and changing views on the Arctic as a tourism destination. Indeed, they are linked to different ontological understandings of the Arctic, which are briefly discussed in relation to case examples and are addressed at a general level in the concluding section with terminological suggestions.

\section{The Arctic in tourism: Complementing and contesting perspectives}


"There is no doubt that tourism in the Arctic is different from tourism in other areas" (Viken, 2013, p. 41)

There seems to be something special or exceptional about the Arctic in tourism as very few other geographical regions are labelled as forms and concepts in tourism. However, based on a broad spectrum of natural and cultural environments, nation states and attractions in the Arctic, formulating a clear and coherent definition for Arctic tourism has turned out to be a challenging task. This is largely based on the fact that the idea and definition of the Arctic itself is highly debatable. Indeed, there are many different ways to limit the region from the rest of the globe (see Arctic Human Development Report [AHDR], 2004; Dodds, 2010; Grenier, 2007, Hall \& Saarinen, 2010b; Maher, 2007; Maher, Stewart \& Lück, 2011; Stonehouse \& Snyder, 2010). In the context of tourism, Maher et al. (2014, p. 1) have noted that "tourism in the Arctic starts at the North Pole and quite literally spreads out in all directions from there." But how far south of those circumpolar lands and seas can be considered Arctic in tourism? Where and how can we locate the borders of the Arctic?

This bordering process of the Arctic is both theoretically and practically difficult task. Although boundaries and bordering often refer to a nation state's affairs, Rumford (2012, p. 887) has stressed that bordering and bounded spaces "are not always the project of the state" as businesses and people can also actively construct and transform borders or in some cases even erase them (see Rumford, 2008; Timothy, Saarinen \& Viken, 2016). Balibar (2002) has further emphasised that borders as socio-political ideas are everywhere, and they can transform and move by being linked to mobile subjects. Indeed, businesses and people, i.e. the tourism industry and tourists, can play a major role in defining what the Arctic means beyond administrative borders in tourism.

According to Hamelin (1968), the term 'Arctic' itself is conceptually challenging as it refers to various regional constellations, and the Arctic space can be divided into several scales and subdivisions such as 'sub-Arctic', 'inner-Arctic', 'outer-Arctic', 'low-Arctic', 'high-Arctic', 'panArctic', etc. In contrast to that, Nuttall (1998) uses different terminology by referring to the Circumpolar North, which includes Arctic and sub-Arctic areas. In addition, there are also different tourism-related terms partly associated with the Arctic region, such as polar tourism (Hall \& Johnston, 1995; Maher, 2007; Stonehouse \& Snyder, 2010) and Nordic tourism (Hall, Müller \& Saarinen, 2009). In general, 'polar' refers to the regions surrounding both the North and the South 
Pole, thus, polar tourism can correspond to almost any kind of tourism activities taking place around the North and South Poles (Enzenbacher, 2011; Grenier \& Müller, 2011; Hall \& Saarinen, 2010a). More specifically, however, "polar tourism refers to the shared environmental, developmental and policy characteristics of the Arctic and Antarctic regions in tourism, including relatively high seasonality of activities and tourism flows" and "the concept emphasizes tourism that is based in high-latitude cryospheric environments" which are highly vulnerable socioecological systems to change (Hall \& Saarinen, 2010b, p. 454; see also Hall, 1992; Slaymaker \& Kelly, 2007). The term 'Nordic' is obviously linked to the northern hemisphere, and 'Nordic tourism' refers generally to any kind of tourism activities taking place in the Nordic countries and territories (Hall, Müller \& Saarinen, 2009), namely Denmark, Finland, Iceland, Norway, Sweden and the associated territories of the Faroe Islands, Greenland and Åland; thus excluding the rest of the Arctic regions (see Hjalager \& Flagestad, 2012).

This conceptual landscape of partly overlapping terminology is not an unusual case in the vocabulary of tourism studies (e.g. nature-based tourism versus ecotourism or ethnic tourism versus indigenous tourism), but it raises critical questions in relation to Arctic tourism, such as: What makes Arctic tourism Arctic? Is all tourism taking place in the region (whatever definition used) Arctic tourism or are there other specific elements and issues involved in making tourism 'Arctic'?

\section{Spatial approach to tourism in the Arctic}

Maher (2007, p. 1) has argued that "Arctic tourism is tourism that occurs in the Arctic." This starting point calls for further clarification as to what the Arctic (region) is? According to Hall and Johnston (1995), both indicators of climate and latitude are commonly used to define the Arctic geographically. More specifically, they refer to the Arctic Circle and/or the tree line as the borders of the Arctic. Stonehouse and Snyder (2010, p. 7) also consider the tree line as the "main ecological boundary" of the Arctic region. In addition, a $+10^{\circ} \mathrm{C}$ isotherm in July and the area of continuous permafrost are common ways to delimit the Arctic (Hall \& Saarinen, 2010b). Obviously the use of the tree line or permafrost over the seas, for example, is not a workable approach, and this gap in the borders of the Arctic over the oceans has been noted by Maher et al., (2011). They have further highlighted the necessity for a more detailed marine delineation, as tourism occurs on the seas - and increasingly so. Based on this they have suggested the "convergence of the colder, less salty water of the Arctic Ocean with the warm, saltier waters of the Atlantic and Pacific" (pp. 5-6) as a potential marine border for the Arctic. 
These 'natural' borders of the Arctic refer to Leiper's (1979) geographical element of tourism. They also relate well with Wang's (1999) idea of objective authenticity (see MacCannell, 1976), which emphasises the real and original nature of objects in tourism. Thus, it is not a matter of individual or social interpretation. Many of these kinds of borders of the Arctic refer to objective (i.e. measurable from a physical environment) 'lines' in space, but they are not static. For example, the tree line as a phytogeographical parameter is highly influenced by global climate change (Arctic Climate Impact Assessment [ACIA], 2005, p. 851), and the same applies to the $+10^{\circ} \mathrm{C}$ isotherm in July and the continuous permafrost. This demonstrates the dynamic nature of the Arctic geography and environment. At the same time, however, it may create challenges for the definition of Arctic tourism based on the changing physical borders and region of the Arctic, i.e. what was Arctic tourism last year may not be Arctic in future years. More importantly, even if these natural borders did not change, the monitoring of the intensity and change of tourism in the Arctic region is practically impossible based on them, as statistical systems of socioeconomic development are usually organised by using administrative and political units and boundaries.

Many scholars have explicitly or implicitly indicated that Arctic tourism refers to all kinds of tourist activities taking place north of the Arctic Circle (see Stonehouse \& Snyder, 2010). Viken (2013, p. 41), for example, has emphasised that "the most common [way] is to treat the polar circles as the lines that demarcate the polar regions." While this may work at a tourism phenomenon level, the regional base structure of statistical systems also hinders the use of the Arctic Circle as an absolute definition of the Arctic border: the Arctic Circle cuts through many administrative units, which makes it very difficult when using tourism statistics to determine on which side of the Arctic Circle overnight stays have taken place, as they would be recorded by municipality, province or country (see Grenier, 2011). In order to overcome this problem, Hall and Johnston (1995) have used the Arctic Circle in combination with political regions linked to the circle (see also Hall \& Saarinen, 2010a, 2010b). This approach allows for the utilisation of existing statistical data on tourism in national and subnational territorial jurisdictions.

Policy-makers and international cooperation institutions have also created their own definitions for the Arctic that have been utilised in tourism research or in regulations and policies. At a political level, several countries and transnational organizations have proposed their own definitions for the Arctic, resulting in a lack of consensus amongst countries as well (Maher, 2007). This highlights the need to have a firm understanding of the idea of Arctic, in general, and in relation to tourism. A key 
institution in Arctic politics and policy-making is the Arctic Council: it is the leading intergovernmental forum promoting collaboration among the Arctic States (Canada, Denmark, Finland, Iceland, Norway, Russian Federation, Sweden and United States), Arctic indigenous communities and other inhabitants in the region. The council does not have a singular definition for the Arctic but it's different working groups have developed and are using suitable definitions for their own focus areas. In addition, different member states have their definitions emphasising the political and economic aspects of the Arctic. For example, for the United States the Arctic corresponds to "all US and foreign territory North of the Arctic Circle and all US territory North and West of the boundary formed by the Porcupine Yukon and Kuskokwin Rivers; all contiguous seas, including the Arctic Ocean and the Beaufort, Bering and Chukchi Seas; and the Aleutian Chain" (US Arctic Research Commission, 2009). In contrast to this circumpolar perspective, Russia uses its own administrative borders to define the Arctic region, corresponding to the whole or parts of "the territories of the Republic of Sakha (Yakutia), Murmansk and Arkhangelsk provinces, Krasnoyarsk territory, Nenets, Yamal-Nenets and Chukchi autonomous districts" (see Russian Federation Policy for the Arctic to 2020).

The Nordic Council of Ministers is another international cooperative institution working with the Arctic. The Council's Arctic Human Development Report (AHDR, 2004, pp. 17-18), for example, combines geodetic, political and natural parameters in its widely used definition for the Arctic (see Grenier, 2011; Hull, 2011, Maher, 2007; Maher et al., 2014; Maher, Stewart \& Lück, 2011). According to the report, the Arctic:

"encompasses all of Alaska, Canada north of $60^{\circ} \mathrm{N}$ together with northern Quebec and Labrador, all of Greenland, the Faroe Islands, and Iceland, and the northernmost counties of Norway, Sweden and Finland. [In]Russia,(...) the Murmansk Oblast, the Nenets, YamaloNenets, Taimyr, and Chukotka autonomous okrugs, Vorkuta City in the Komi Republic, Norilsk and Igsrka in Krasnoyarsky Kray, and those parts of the Sakha Republic whose boundaries lie closest to the Arctic Circle."

Again, while the AHDR's (2004) definition is widely used and it aims to be comprehensive and regionally inclusive, with large regions south of the Arctic Circle, it presents problems in the context of tourism. For example, the city of Churchill, in Manitoba, Canada, is the 'polar bear capital of the world' with many tourism operators engaged in polar bear tours and sledge dog safaris, etc. (Dawson, Stewart \& Scott, 2010). Thus, "placing Churchill [...] outside the Arctic" 
(Maher, 2007, p. 2) does not reflect the Arctic as a tourism product and destination or an individually experienced place called the Arctic (see Grenier, 2004).

\section{Produced Arctic in tourism}

According to the common phrase, there is nothing real or authentic in tourism (see Boorstin, 1964; MacCannell, 1976). While this may be a provocative statement, there is also a reasoning behind the phrase, as a large share of the products and performances in tourism are what Brown (1996, p. 33) has critically called "genuine fakes". These kinds of products are based on the industrial constructions (see Leiper, 1979), which may refer to and utilise the idea of authenticity and realness, but they are not authentic in an objective sense (see Taylor, 2001; Trilling, 1972). Instead, it is somehow agreed that they are and represent authenticity (Wang, 1999).

The Arctic Circle as the border of the Arctic can also be reinterpreted from this perspective. The Arctic Circle is fixed in the coordination system, located at $66^{\circ} 33^{\prime} \mathrm{N}$, but just like phytogeographic boundaries, it is also influenced by a natural phenomenon, namely the Earth's obliquity of the ecliptic (Berger, 1976). What this basically means is a major shifting of the latitude position of the Arctic Circle in relation to the sun. Thus, objectively the Arctic Circle is mobile but socially spatialised (Shields, 1991) and the fixed latitude is agreed and manifested in certain locations, such as Santa Claus Village in Rovaniemi, Finland (Figure 1).

INSERT Figure 1 about here

Figure 1. The Arctic Circle signpost in Rovaniemi, Finland (Photo: author)

The produced Arctic in tourism is based on Leiper's (1979) industry element and its activities and products that refer to a socially constructed idea of what Arctic environments and cultures are or should be (see Lund, Kjartansdóttir \& Loftsdóttir, 2017). According to Urry (1990), tourists are seeking destinations that are the opposite of their everyday lives; places where they can experience "natural, historical or cultural extraordinariness" (Rojek, 1997, p. 52). These kinds of tourism products and activities representing the 'extraordinary' or a distinction from everyday life and environments are co-created with and supported by references to popular images, depictions and stereotypes of the Arctic, as well as social media and travelogues, for example (Rojek \& Urry, 
1997; Urry, 1995). Based on this, Arctic tourism can refer to various kinds of tourism activities taking place north of the Arctic Circle or inside the area defined by the AHDR (2004), but at the same time it is not limited to these regional units. Arctic tourism products and activities can also take place south of the Arctic Circle: e.g. in Kemi, Finland, where icebreaker tours through the frozen Bothnian Bay are advertised next to the Snow Castle, or the Arctic (wildlife) tourism that takes place on the outskirts of the previously mentioned town of Churchill, Canada, in the form of polar bear tours. Thus, Arctic tourism takes place where it can be produced by utilising, modifying and commercialising cultural and popular images, representations and identities that refer to Arctic environments.

In the tourism authenticity literature, the produced perspective on Arctic tourism is often called staged authenticity (MacCannell, 1973, 1976; see also Bruner, 1991; Goffman, 1959). Staged Arctic tourism is about products, activities and performances involving "toured objects" (Wang, 1999, p. 351), such as attractions, sites, rituals and ceremonies that may be simplified, shortened, embellished, "or otherwise adopted to the tastes of the tourists" (Cohen, 1988, p 381; see also Cohen, 1983; Pashkevich \& Keskitalo, 2017). In order to find out and demonstrate what kinds of tourism products linked to 'Arctic' are provided, a simple descriptive analysis can be used for illustrative purposes. This selected example using an Internet search was limited to those tourism businesses using the term 'Arctic' in their name in Rovaniemi (Finland), Tromsø (Norway), Longyearbyen, Svalbard (Norway), Reykjavik (Iceland), Fairbanks, Alaska (USA), Whitehorse, Yukon and Iqaluit, Nunavut (Canada), Sisimiut (Greenland) and Yakutsk (Russia). These sites represent well-known tourism hubs linked to 'Arctic tourism' but they are not necessarily located inside a spatially defined Arctic. They do not aim to be fully representative, rather, they aim to be demonstrative, serving the following illustrative example.

In total, 560 activities being offered using the name 'Arctic' were counted. Briefly, in Rovaniemi, among the 112 activities on offer, about 18 per cent was based on snowmobiling, followed by reindeer-based activities (e.g. visiting reindeer farms and reindeer sledding) (14\%). Viewing the Northern Lights represented approximately 10 per cent of the activities on offer. In addition, there were other 'Arctic' tourism activities such as husky safaris, fishing/ice fishing and visits to Santa Claus village (on the Arctic Circle) in Rovaniemi. In contrast, Tromsø offered 78 products which were largely related to boat tours (31\%), especially whale-watching trips. Northern Lights related activities covered about 19 per cent and reindeer related products about 10 per cent of the total activities. Other available Arctic activities were linked to Sami culture and husky safaris. In 
Reykjavik a total of 123 'Arctic' activities were identified and among them, sightseeing was the largest activity group, covering approximately 40 per cent of all tourism products. These included tours based on $4 \times 4$ vehicles, helicopters and all-terrain vehicles (ATVs). Visited places included the Golden Circle (a circular tour of the island) sites and/or the Icelandic wilderness (Highlands). Rafting formed 10 per cent, followed by hiking, Northern Lights viewing and horse riding (each approximately 7\%). In addition, boat tours (whale watching), glacier hikes, ice caving and snowmobiling were offered under the concept of 'Arctic' in Reykjavik. In Longyearbyen, 64 activities were counted: the main Arctic tourism products were snowmobile safaris (approximately $30 \%$ ) and boat tours (approximately 27\%). Safaris and tours included Arctic wildlife viewing and/or visits to cultural sites such as Pyramiden or Barentsburg. Guided summer hikes covered about 20 per cent of the activities. In addition, skiing and general sightseeing were also offered as 'Arctic' tourism activities.

In Fairbanks, 53 activities were identified as 'Arctic'. Dogsledding was the most visible and represented one third of all products, followed by sightseeing (19\%) and rafting (17\%). Sightseeing included car tours of around local areas (e.g. Arctic Circle landmark) and flights tours. Other 'Arctic' activities were related to Northern Lights viewing and wildlife safaris (mostly caribou). In Whitehorse, Canada, among the 74 'Arctic' activities on offer 23 per cent were focused on to Northern Lights, 16 per cent on sightseeing and guided tours, and 11 per cent on wildlife safaris. In addition, other activities were products referring to the First Nations, snowmobiling, visiting hot springs, fishing and dogsledding. Iqaluit had 17 activities under the name of 'Arctic'. Almost half (41\%) were based on wildlife safaris (mostly polar bears and whales) and about 24 per cent on sightseeing tours across the Baffin Island and other northern communities. Both photography tours and snowmobiling covered over 10 per cent. Among 22 'Arctic' activities on offer in Sisimiut, sightseeing flights or boat tours were dominant products (41\%), followed by dogsledding and guided hikes (both 18\%) and by fishing/ice-fishing (13\%). Both Iqaluit and Sisimiut had also northern lights viewing on offer. Finally, in Yakutsk, Russia, 17 'Arctic' activities were identified, with a majority (35\%) related to indigenous culture (e.g. reindeer husbandry). In addition, there were gulag visits, hunting mammoth bones, hiking and sightseeing products, each of which accounted for about 10 percent of the overall offerings. Other activities under the name of 'Arctic' in Yakutsk were snowmobiling, dog sledding and wildlife safaris.

Based on this short overview of Arctic tourism products in selected circumpolar destinations, it seems that the tourism industry acknowledges the diversity of the Arctic. Businesses adapt their 
Arctic tourism products to local contexts and environments. For example, in coastal Tromsø the dominant activity was boat tours and in Reykjavik the tourism operators used the relatively easy access to wilderness environments in their sightseeing products. This is as one would expect. There are also common activities forming the core of Arctic tourism products almost despite their location in the Arctic. Those core products are related to snowmobiling and viewing the Northern Lights. In addition, reindeer-related (or caribou) products were relatively widely present. Altogether, these three product groups represent well over 40 per cent of the total Arctic tourism activities in the Nordic Arctic. However, in North America (including Greenland) these core products represent only about 20 per cent of the total activities (due to a large presence of sightseeing activities). Thus, interestingly, the idea of 'Arctic' is commercialized partly differently in North America compared to the European Arctic. In Canada and United States sightseeing and touring activities to remote 'Arctic' locations form a clear majority of the products. These small-scale exclusive sightseeing tours, which are often relatively expensive, are opposite to a packaged mass-scale tourism products and practices in Rovaniemi and Tromsø, for example. These main Arctic activity sets in the European and North American destinations obviously benefit from their physical location inside or close to the Arctic region. Therefore, the produced and spatially defined 'Arctics' in tourism are complementing each other in nature-based tourism activities. However, the cultural elements of the spatial Arctic are not represented as visibly in the produced one. Although a reindeer/caribou as a semi-domesticated animal represents a culture and is a cultural icon, the analysed Arctic tourism products are largely based on game viewing rather than a cultural approach.

With the exception of Yakutsk, there seems to be a lack of cultural elements in Arctic tourism. We can assume that this outcome is not based on the selected case example sites being non-cultural. Reykjavik, Fairbanks, Rovaniemi and Tromsø are major urban centres with rich cultural life and activities, but it seems that the produced Arctic tourism refers to common representations of the Arctic characterised by empty spaces and adventures in frozen, untouched and uncivilised landscapes (Hanrahan, 2017). Thus, the way the Arctic is produced and marketed by the industry influences the image of the region and creates a set of expectations for tourists before actual visitation (Buhalis, 2000). In this context, Buhalis further states that tourism marketing can operate as a mechanism facilitating local regional development objectives: the goals of the produced Arctic perspective are therefore to attract tourists in the region for socio-economic growth purposes, but also to support the realization of local and regional tourism policies. The tourism industry does not create these kinds of activities and products in a vacuum; as indicated they are supported by historical, colonial and popular narratives and cultural representations of what the Arctic and the 
Arctic tourism are about. The Arctic is a harsh, wild and empty environment to visit and conquer. Thus, the perspective on the Arctic is often dominated by outsiders' views and is targeted at outsiders, i.e. the tourists, for them to experience.

\section{Experienced Arctic in tourism}

According to Hall and Saarinen (2010b) well over five million tourist visits occur annually in the Arctic and sub-Arctic. Provided activities and socially constructed representations of the Arctic in tourism aim to satisfy this tourism demand and the needs of visiting tourists. At the core of the demand are tourist experiences, referring to the crucial human element in tourism (Leiper, 1979). For Wang (1999), tourist experiences can be object-related or activity-related. Here, the former refers to constructed authenticity in tourism which is supported by the previously discussed spatial and produced perspectives of the Arctic. The latter is an existential and highly subjective view of the Arctic that may have a very loose relation with the Arctic region. As noted by Wang (1999, p. 359): "existential authenticity [... can often have nothing to do with the issue of whether toured objects are real." Thus, the spatial and produced perspectives of the Arctic may guide the experienced Arctic, but despite the nature of the guiding frames a tourist can have or not have an Arctic tourism experience (see Hamelin, 1979). This relates to Balibar's (2002) notion of mobile (Arctic) borders, embodied here in travelling tourists and their experiences.

Based on the literature, and the previously analysed Arctic tourism products, tourist experiences of the Arctic are largely related to the natural environment (see Grenier, 2004; Jóhannesson, Huijbens \& Sharpley, 2010; Lee, Weaver \& Prebensen, 2017; Saarinen, 2005; Sæpórsdóttir, 2010; Viken, 2013). Seasonality in nature characterises the Arctic but its role is not always acknowledged in the definitions of Arctic tourism and experiences. A recent report 'Arctic Business Analysis: Creative and Cultural Industries' by the Nordic Council of Ministers (2018, p. 23), for example, defines Arctic tourism as "tourism based in high latitude environments characterized by cold and extreme nature, involving nature-based, culture-based and sports-based activities". The definition overlooks the seasonality and internal dynamics of Arctic environments and conditions: What about tourism in the high latitudes in summer months when conditions are not necessarily cold and extreme?

Seasonality is typically regarded negatively in tourism development literature and discourses, but in the Arctic it also creates additional attractiveness by offering a diverse base for Arctic tourism experiences. For example, Arctic summers and winters attract tourists respectively because of the 
midnight sun phenomenon and the Northern Lights. As they cannot be experienced during the same trip, follow-up visits are needed in order to discover the variety that the Arctic offers (Johnston, 2011; Viken, 2013). However, from the tourist experience perspective the idea that all tourism seasons and activities existing and offered in the region (and even under the banner of Arctic tourism products) represent Arctic tourism is a problematic one. For some tourists the Arctic may refer to snow- and ice-covered landscapes alone, and therefore for them an Arctic summer could be an oxymoron. Tourism in the Arctic also includes activities and products that are available globally, such as hiking, shopping and spa and wellness tourism, and predicting how those activities are experienced by individual tourists is difficult. In this respect the Arctic can be unique to each individual and what seems real is "the result of the versions of our interpretations" (Wang, 1999, p. 354).

However, although potentially highly personal, these interpretations of the Arctic are not processed in total solitude. Tourist experiences can be interpersonal, i.e. shared ones, and they are often seen as being based on a search for signs or symbols of needed experiences that reflect the stereotyped representations of tourist-sending societies and cultures (MacCannell, 1976; Urry, 1990; Wang, 1999). For example, the 'Arctic Circle Crossing Ceremony' offered in Rovaniemi (Finland) promises a magical and exotic cultural experience:

\footnotetext{
"Crossing the magical line of the Arctic Circle has been considered a great achievement already decades ago. Nowadays, it's not only possible to cross the line but to make the experience even more memorable with a genuine Arctic Circle Crossing Ceremony. The ceremony takes place in a traditional KAMMI where the participants sit around the fire, enjoying juice made from Lappish berries. A shaman who also tells stories about Lapland arranges the ceremony. Atmosphere of the ceremony is very exotic. As a proof, as well as a concrete memory of the Arctic Circle Crossing, every participant receives the original Arctic Circle Crossing Certificate."
}

This Arctic Circle Ceremony, which is supposed to be "genuine" or "authentic" is an example of the commoditisation of cultures in the Arctic in order to offer experiences seen as real from a Western tourist point of view. The shamanistic practices referring the indigenous Sami culture are modified for tourism purposes, and during the ceremony the geodetic line of the Arctic Circle is conflated with Sami culture as representing a 'magical line' in a ceremony hosted by a shaman, which has nothing to do with the indigenous culture. A similar example can be found in the village 
of Jokkmokk, northern Sweden, where a new tour for visitors was launched in summer 2017 called 'Art and Design of Sápmi' (see: www.jokkmokk.se). The tour offers an experience with a "unique insight into Sami art, crafts and design" where the Arctic Circle is associated with Sami culture and authentic indigenous crafts.

These examples from Rovaniemi and Jokkmokk demonstrate that cultural elements can be linked to the Arctic. In tourism this connection is often processed by "a mystification designed to generate a sense of real reality" (MacCannell, 1973, p. 591) and the outcomes of this are most probably "judged as inauthentic or staged authenticity by experts, intellectuals, or the elite" (Wang, 1999, p. 353). Still, they may be experienced as authentic and real by visiting tourists. This raises potential ethical questions in relation to the produced Arctic and the use of cultural elements and physical environments in Arctic tourism, i.e. are there limits to how to depict local cultures or modify and use the (Arctic) environment in tourism (see Saarinen, 1999, 2005). Although these are highly crucial questions, they are beyond the scope of this paper.

\section{Discussion and conclusions}

There is a relatively widely acknowledged idea of exceptionalism in the Arctic in tourism (Viken, 2013) but there is no consensus on the concept of Arctic tourism. Indeed, as indicated by Maher (2007) the aim to provide a single comprehensive definition for Arctic tourism may be an impossible task. For example, a definition of Arctic tourism that refers to all kinds of tourism activities taking place in the Arctic could be feasible, but only if we do not problematize the social and political idea of the Arctic and its boundaries. In addition, even if we were to acknowledge that there is a more or less agreed spatial definition of the Arctic, such as the Arctic Circle or the AHDR's (2004) definition, it is not necessarily operational with the tourism phenomenon (the industry and the human element) referring to a diverse, potentially changing and highly contextual set of ecological, political, economic and sociocultural Arctic environments, activities and experiences in tourism.

Thus, instead of thinking about an all-inclusive definition for Arctic tourism, this paper outlines perspectives from which the Arctic could be approached and framed in tourism. These outlined perspectives, namely the spatial, produced and experienced Arctics in tourism, represent general frameworks - contexts - demonstrating different potential ways of approaching and understanding 
various characteristics of and diversity in Arctic tourism (Table 1). From a spatial perspective, the Arctic is a geographically defined region with a set of boundaries that can be based on natural and/or political criteria. The produced Arctic in tourism is a destination and tourism product that reflects a socially and economically produced and reproduced idea of the Arctic. It is grounded on the industry (see Leiper, 1979) by being a tourism-centric space for economic growth serving the industry and its development goals in the region. The experienced Arctic is a tourist-centric and subjective place for which the spatial and produced Arctic provide a context, but the experienced view is not necessarily limited to them: the Arctic tourist experience may or may not happen in the (spatial and/or produced) Arctic.

\section{INSERT TABLE 1 ABOUT HERE}

Table 1: Key perspectives of the Arctic in tourism

All these perspectives of the Arctic in tourism involve some limitations (see Table 1), and the perspectives are obviously interrelated and dynamic. The common ground that they cover represents an 'Arctic frontier' in tourism in which the spatial, produced and experienced Arctics collide and form a dynamic and transforming structure in which Arctic tourism can exist. By acknowledging the diversity of the region, the Arctic frontier is not only based on external views and needs concerning the Arctic space, but it also incorporates internal socioeconomic, cultural and environmental knowledge, needs and concerns in the Arctic. From this inter-relational perspective the Arctic is not primitive or remote per se but also involves internal cores and peripheries - just like any other region in the world. This partly contrasts with the traditional view of the Arctic as being mainly defined by outsiders to outsiders in tourism development and consumption.

However, as indicated, these perspectives are not necessarily complementary but can also open up contested and conflicting views on what the Arctic in tourism is (for). The relationships between the spatial and produced and spatial and experienced Arctics can be particularly problematic, as conflicts in those relations may involve issues related to the ecological and sociocultural sustainability of tourism. In addition, from the tourism industry's perspective, a possible conflict between the produced and experienced Arctic indicates an economic sustainability challenge for the industry in the long run (i.e. if supply and demand do not meet or if the benefits and costs of tourism are shared unequally). Moreover, if we take a specific perspective as granted and do not acknowledge the existence of alternative views and diversity in the Arctic, we may (un)intentionally exclude prospective development paths that could serve local and regional development needs in 
future. For example, if we perceive and conceptualise Arctic tourism based on the externally constructed views of the region as cold, harsh, wild and empty environment, we may encounter great difficulties in creating tourism policies and development goals that serve the social realities of local communities and increasingly urbanised environments in the Arctic region (see Nordic Council of Minister, 2011, p. 22-37).

Despite the perspective, one key question remains: what makes the Arctic special in terms of tourism? Although this review paper did not aim to define the essence of the Arctic or the concept of Arctic tourism per se, the outlined perspectives acknowledging the diversity of the region have implications for the ways we should think about Arctic in tourism. As noted the Arctic diversity problematises the nature/culture dichotomy in tourism, but it also further challenges the current and conventional conceptual understanding of Arctic tourism. Unlike many other forms of tourism, such as urban tourism, nature-based tourism, lake tourism and indigenous tourism, Arctic tourism, with its diversity and multitude of elements, cultures and environments, does not necessarily refer to a certain kind of attraction element or related tourism activities. Indeed, all the above-mentioned forms of tourism can also be practised in the contemporary Arctic. Still, the idea of Arctic tourism is often tied into limited views on cold and empty landscapes.

Thus, the concluding argument is that in research and policy-making we should be more specific about our perspective of (spatial, produced and experienced) Arctic in tourism. As noted, if our understanding of tourism in the Arctic is limited then the policies that we develop in relation to it are likely to be limited too. Obviously, Arctic tourism per se is widely recognised and used term that has a promotional and selling value, but academically there may not be a firm ground for such 'Arctic exceptionalism' when compared with other geographical regions used in tourism: simply, we do not have Sahara tourism, Amazon tourism or Siberia tourism, for example. Therefore, instead of conceptually vague and singular Arctic tourism, a use of more specific terminology such as Arctic urban tourism, urban tourism in the Arctic, Arctic nature-based tourism or Arctic indigenous tourism, for example, would be more precise. This would also empower a wider spectrum of tourism products and development paths in the Arctic, which would not be limited to historically contingent constructs created by outsiders, for outsiders. This kind of diversified and decolonising tourism vocabulary and related policy and development discourses would also serve indigenous tourism development and increasingly urbanised communities and transforming tourism industry in the Arctic in future. 


\section{References}

Arctic Climate Impact Assessment (2005). Arctic Climate Impact Assessment. Cambridge: Cambridge University Press.

Arbo, P., Iversen, A., Knol, M., Ringholm, T., \& Sander, G. (2013). Arctic futures: conceptualizations and images of a changing Arctic. Polar Geography, 36(3), 163-182.

Arctic Human Development Report (2004). Arctic Human Development Report. Akureyri: Arctic Council, Stefansson Arctic Institute.

Balibar, E. (2002). Politics and the other scene. London: Verso.

Berger, A.L. (1976). Obliquity and precession for the last 5000000 years. Astronomy and Astrophysics, 51, 127-135.

Boorstin, D.J. (1964). The image: a guide to pseudo-events in America. New York, NY: Atheneum.

Brown, D. (1996). Genuine fakes. In T. Selwyn (Ed.), The tourist image: myths and myth making in tourism (pp. 33-47). Chichester: Wiley.

Bruner, E.M. (1991). Transformation of self in tourism. Annals of Tourism Research, 18(2), 238250.

Buhalis, D. (2000). Marketing the competitive destination of the future. Tourism management, 21(1), 97-116.

Bystrowska, M., \& Dawson, J. (2017). Making places: the role of Arctic cruise operators in 'creating' tourism destinations. Polar Geography, 40(3), 208-226.

Cohen, E. (1983). The dynamics of commercialized arts: the Meo and Yao of Northern Thailand. Journal of the National Research Council of Thailand, 15(1), 1-34. 
Cohen, E. (1988). Authenticity and commoditization in tourism. Annals of Tourism research, 15(3), 371-386.

Dawson, J., Stewart, E., \& Scott, D. (2010). Climate change and polar bear viewing: a case study of visitor demand, carbon emissions and mitigation in Churchill, Canada. In C. M. Hall \& J. Saarinen (Eds.), Tourism and change in polar regions (pp. 89-103). Abingdon: Routledge.

Dittmer, J., Moisio, S., Ingram, A., \& Dodds, K. (2011). Have you heard the one about the disappearing ice? Recasting Arctic geopolitics. Political Geography, 30(4), 202-214.

Dodds, K. (2010). A Polar Mediterranean? Accessibility, Resources and Sovereignty in the Arctic Ocean. Global Policy, 1(3), 303-311.

Enzenbacher, D.J. (2011). Polar tourism development: who benefits. In A.A. Grenier \& D.K. Müller (Eds.), Polar tourism: a tool for regional development, (pp. 23-56). Québec, QC: Presses de l’Université du Québec.

Grenier A.A. \& Müller, D.K. (Eds.)(2011). Polar tourism: a tool for regional development. Québec, QC: Presses de l’Université du Québec.

Fjellestad, M.T. (2016). Picturing the Arctic. Polar Geography, 39(4), 228-238.

Goffman, E. (1959). The presentation of self in everyday life. New York, NY: Doubleday.

Grenier, A.A. (2004). The nature of nature tourism. Rovaniemi: University of Lapland Press.

Grenier, A.A. (2007). The diversity of polar tourism. Some challenges facing the industry in Rovaniemi, Finland. Polar Geography, 30(1-2), 55-72.

Grenier, A.A. (2011). Conceptualization of polar tourism: mapping an experience in the far reaches of the imaginary. In A. A. Grenier \& D. K. Müller (Eds.), Polar tourism: a tool for regional development (pp.61-86). Québec, QC: Presses de l’Université du Québec.

Hall, C.M. (1992). Tourism in Antarctica: activities, impacts, and management. Journal of Travel Research, 30, 2-9. 
Hall, C.M. (2005). Tourism: rethinking the social science of mobility. Harlow: Prentice-Hall.

Hall, C.M., \& Johnston, M.E. (1995). Introduction: pole to pole: tourism issues, impacts and the search for a management regime in polar regions. In C.M. Hall \& M.E. Johnston (Eds.), Polar tourism: tourism in the Arctic and Antarctic regions (pp. 1-26). Chichester: Wiley.

Hall, C.M., Muller, D.K., \& Saarinen, J. (2009). Nordic tourism: issues and cases. Bristol: Channel View Publications.

Hall, C.M., \& Saarinen, J. (2010a). Polar tourism: definitions and dimensions. Scandinavian Journal of Hospitality and Tourism, 10(4), 448-467.

Hall, C.M., \& Saarinen, J. (2010b). Tourism and change in the polar regions: introductiondefinitions, locations, places and dimensions. In C. M. Hall \& J. Saarinen (Eds.), Tourism and change in polar regions: climate, environments and experiences (pp. 1-41). Abingdon: Routledge.

Hamelin, L.-E. (1968). Un indice circumpolaire [A circumpolar index]. Annales de géographie, $422,414-430$.

Hamelin, L.-E. (1979). Canadian nordicity: it's your north too. Montréal, QC: Harvest House Limited Pub.

Hanrahan, M. (2017). Enduring polar explorers' Arctic imaginaries and the promotion of neoliberalism and colonialism in modern Greenland. Polar Geography, 40(2), 102-120.

Hjalager, A.M., \& Flagestad, A. (2012). Innovations in well-being tourism in the Nordic countries. Current Issues in Tourism, 15(8), 725-740.

Hull, J. S. (2011). Sub-arctic tourism introduction. In P. T. Maher, E.J. Stewart \& M. Lück (Eds.), Polar tourism: human, environmental and governance dimensions (pp. 187-205). Putnam Valley, NY: Cognizant Communication Corporation. 
Jokkmokk Municipality. (2017, September 11). Retrieved from http://www.jokkmokk.se/Nyheteroch-Event/Nyheter/Turism/art-and-design-of-sapmi--en-heldag-av-upplevelser-med-konst--ochdesignfokus/

Jóhannesson, G.T., Huijbens, E.H., \& Sharpley, R. (2010). Icelandic tourism: past directions future challenges. Tourism Geographies, 12(2), 278-301.

Johnston, M.E. (2011). Arctic tourism introduction. In P.T. Maher, E. J. Stewart \& M. Lück (Eds.), Polar tourism: human, environmental and governance dimensions (pp. 17-32). Putnam Valley, NY: Cognizant Communication Corporation.

Lund, K.A., Kjartansdóttir, K., \& Loftsdóttir, K. (2017). "Puffin love": Performing and creating Arctic landscapes in Iceland through souvenirs. Tourist Studies, 1-17. DOI:

https://doi.org/10.1177/1468797617722353

Keskitalo, C. (2007). International region-building: development of the Arctic as an international region. Conflict and Cooperation, 42(2), 187-205.

Lee, Y.-S., Weaver, D. \& Prebensen, N.K. (2017). Arctic Tourism Experiences: Production, Consumption and Sustainability. Wallingford: CAB International.

Leiper, N. (1979). The framework of tourism: Towards a definition of tourism, tourist, and the tourist industry. Annals of tourism research, 6(4), 390-407.

MacCannell, D. (1973). Staged authenticity: arrangements of social space in tourist settings. American Journal of Sociology, 79(3), 589-603.

MacCannell, D. (1976). The tourist. New York, NY: Schocken Books.

Maher, P.T. (2007). Arctic tourism: a complex system of visitors, communities, and environments. Polar Geography, 30(1-2), 1-5.

Maher, P.T. (2017). Tourism Futures in the Arctic. In K. Latola \& H. Savela (Eds.) The Interconnected Arctic-UArctic Congress 2016 (pp. 213-220). Cham: Springer. 
Maher, P.T., Gelter, H., Hillmer-Pegram, K., Hovgaard, G., Hull, J., Jóhannesson, G.T., ... Pashkevich, A. (2014). Arctic tourism: realities and possibilities. In L. Heininen, H. Exner-Pirot \& J. Plouffe (Eds.), Arctic yearbook 2014 (pp. 290-306). Akureyri: Northern Research Forum.

Maher, P.T., Stewart, E.J., \& Lück, M. (2011). An introduction to polar tourism: human, environmental, and governance dimensions. In P.T. Maher, E.J. Stewart \& M. Lück (Eds.), Polar tourism: human, environmental and governance dimensions (pp. 3-13). Putnam Valley, NY: Cognizant Communication Corporation.

Nordic Council of Minister (2011). Megatrends. TemaNord, 2011: 527.

Nordic Council of Ministers (2018). Arctic Business Analysis: Creative and Cultural Industries. Copenhagen: Norsk Ministerråd. https://doi.org/10.6027/ANP2018-708

Nuttall, M. (1998). Protecting the Arctic: indigenous peoples and cultural survival. New York, NY: Routledge-Harwood.

Pashkevich, A., \& Keskitalo, E.C.H. (2017). Representations and uses of indigenous areas in tourism experiences in the Russian Arctic. Polar Geography, 40(2), 85-101.

Pincus, R., \& Ali, S.H. (2016). Have you been to 'The Arctic'? Frame theory and the role of media coverage in shaping Arctic discourse. Polar Geography, 39(2), 83-97.

Rojek, C. (1997). Indexing, dragging and the social construction of tourist sights. In C. Rojek \& J. Urry (Eds.), Touring cultures: transformations of travel and theory (pp. 52-74). London: Routledge.

Rojek, C., \& Urry, J. (1997). Touring cultures: transformation of travel and theory. London: Routledge.

Rumford, C. (2008). Citizens and borderwork in contemporary Europe. London: Routledge.

Rumford, C. (2012). Towards a multiperspectival study of borders. Geopolitics, 17, 887-902. 
Russian Federation Policy for the Arctic to 2020 (2018, March 12). Retrieved from http://www.arctis-search.com/Russian+Federation+Policy+for+the+Arctic+to+2020

Saarinen, J. (1999). Representations of indigeneity: Sami culture in the discourses of tourism. In P.M. Sant \& J.N. Brown (Eds.), Indigeneity: constructions and re/presentations (pp. 231-249). New York, NY: Nova Science Publishers.

Saarinen, J. (2004). 'Destinations in change': the transformation process of tourist destinations. Tourist Studies, 4, 161-179.

Saarinen, J. (2005). Tourism in northern wildernesses: nature-based tourism development in Northern Finland. In C. M. Hall \& S. Boyd (Eds.), Nature-based tourism in peripheral areas: development or disaster? (pp. 36-49). Clevedon: Channel View Publications.

Saarinen, J. (2014). Critical Sustainability: Setting the Limits to Growth and Responsibility in Tourism. Sustainability 6(11), 1-17.

Sæpórsdóttir, A.-D. (2010). Planning nature tourism in Iceland based on tourist attitudes. Tourism Geographies, 12(1), 25-52.

Sæpórsdóttir, A-D. \& Saarinen, J. (2016). Challenges due to Changing Ideas of Natural Resources: Tourism and Power Plant Development in the Icelandic Wilderness. Polar Record, 52(1), 82-91.

Sæpórsdóttir, A.-D., Hall, C.M., \& Saarinen, J. (2011). Making wilderness: tourism and the history of the wilderness idea in Iceland. Polar Geography, 34(4), 249-273.

Shields, R. (1991). Places on the margin. Alternative geographies of modernity. London: Routledge.

Slaymaker, O., \& Kelly, R.E.J. (2007). The cryosphere and global environmental change. Oxford: Blackwell. 
Staalesen, A. (2017, June). Bigger cruise ships, more tourists sail into Svalbard waters. The Barents Observer. Retrieved from https://thebarentsobserver.com/en/arctic/2017/06/bigger-cruise-shipsmore-tourists-sail-svalbard-waters

Stonehouse, B., \& Snyder, J. (2010). Polar tourism: an environmental perspective. Bristol: Channel View Publications.

Taylor, J.P. (2001). Authenticity and sincerity in tourism. Annals of Tourism Research, 28(1), 7-26.

Timothy, D. Saarinen, J., \& Viken, A. (2016). Tourism issues and international borders in the Nordic region. Scandinavian Journal of Hospitality and Tourism, 16(1), 1-13.

Trilling, L. (1972). Sincerity and authenticity. London: Oxford University Press.

Urry, J. (1990). The tourist gaze: leisure and travel in contemporary societies. London: Sage Publications.

Urry, J. (1995). Consuming places. London: Routledge.

US Arctic Research Commission (Allison Gaylord) (2009). Arctic Boundary as defined by the Arctic Research and Policy Act (ARPA) [Bordering map]. Retrieved from https://storage.googleapis.com/arcticgov-static/publications/maps/ARPA_Polar.pdf

Viken, A. (2011). Tourism, research, and governance on Svalbard: a symbiotic relationship. Polar Record, 47(4), 335-347.

Viken, A. (2013). What is Arctic tourism, and who should define it? In D. K. Müller, L. Lundmark \& R. H. Lemelin (Eds.), New issues in polar tourism: communities, environment, politics (pp. 3750). New York, NY: Springer.

Viken, A., \& Müller, D.K. (2017). Tourism and indigeneity in the Arctic. Bristol: Channel View Publications. 
Wang, N. (1999). Rethinking authenticity in tourism experience. Annals of Tourism Research, 26(2), 349-370.

Wilson Rowe, E. (2013). A dangerous space? Unpacking state and media discourses on the Arctic. Polar Geography, 36(3), 232-244. 